\title{
Research on the Evaluate of Chinese Smart-city Spatiotemporal Information Cloud Platforms \\ Chengming $\mathrm{Li}^{\star}, \mathrm{Xiaoli}$ Liu and Jie Yin
}

Chinese Academy of Surveying and Mapping, 28 Lianhuachi West Road, Beijing, China

\section{Abstract}

Publication History:

In order to clearly evaluate city intelligence capabilities for the construction of smart-city spatiotemporal Received: October 25, 2017 information cloud platforms and evaluate their effectiveness, this study proposed a general framework and Accepted: December 13, 2017 evaluation elements for construction evaluation-index systems suited for such platforms. Tests for selected Published: December 15, 2017 cities were scored so that they may provide support for smart-city construction. This study was according to in accordance with the National Evaluation-Index Systems of Smart Cities and its requirements for the establishment of departmental evaluation indices. According to the test results, we modified and improved the indices. This may now be used to guide and promote cities to conduct construction of spatiotemporal information cloud platforms in a purposeful, well-planned, and step-by-step manner.

\section{Keywords:}

Spatiotemporal information, Framework, Smart cities, Evaluation index, Evaluation elements

\section{Introduction}

Since the initiation of pilot construction of the spatiotemporal information cloud platform of smart cities by the National Administration of Surveying, Mapping, and Geo information (NASMG) in 2012, more than 30 cities have been chosen as pilot cities to construct smart-city spatiotemporal information cloud platforms. Meanwhile, some cities with a good construction foundation for a digital-city geospatial framework have been committed to transforming themselves into smart cities by upgrading platforms, deepening applications, and conducting intelligent constructions [1]. According to the 2016 NASMG working conference report of surveying, mapping, and geo information, digital-city construction has been widely initiated in all the 333 prefecture-level cities and 476 county-level cities nationwide. These cities are committed to promoting an upgrade from digital cities to smart cities [2].

When faced with such a massive scale of construction, evaluating whether the spatiotemporal information cloud platform of a smart city is really smart and their level of intelligence and effectiveness is a critical task. When designing construction in the early period, implementing the design in the middle period, and conducting self-evaluation in the late period, this will require administrative departments to specify evaluation indices on the one hand and construction departments to use the indices on the other hand. Only by doing so will the construction adhere to the plan and lead to a tangible outcome.

\section{Background}

Recently, China has started to explore smart-city evaluation indices on a national scale. In August 2014, eight departments including the National Development and Reform Commission (NDRC) jointly released, Instructions about promoting healthy development of smart cities, (development-reform high-tech [2014] 1770) [3] that clearly required, a faster research and development of standard systems and evaluation systems for smart-city construction. In order to implement the instructions, NDRC organized 26 departments to form an interdepartment coordination working group for promoting the healthy development of smart cities [4] and establish working plans that specified the work focus of each department. In particular, they prioritized the organization of each department to research and establish a unified smart-city evaluation index system as a main task of the working group.
Among the 26 departments, Standardization Administration of China (SAC) is responsible for establishing a general framework of smart-city Evaluation-Index Systems on a national level. Each of the other departments will establish an evaluation index system in their corresponding fields under the general framework. In January 2015, SAC released the General Framework of Smart-city EvaluationIndex Systems (draft for comment) [5], the General Requirement for Establishment of Each Sub-item in Smart-city Evaluation-Index Systems (draft for comment) [6], and with relevant departments established the National Evaluation Indices of Novel Smart Cities (draft for comment) [7] in April 2016. The release of these regulations and files on a national level provides a support and guidance, from a perspective of the general framework, for NASMG to research and establish a construction evaluation-index system of smart-city spatiotemporal information cloud platforms.

Although the regulations and files released by China provide a general framework and a standard scheme for the research of construction evaluation-index systems suited for smart-city spatiotemporal information cloud platforms, the selection of evaluation indices and the determination of evaluation methods requirements need to be closely linked to the construction content of the smart-city spatiotemporal information cloud platforms. From the construction of a digital-city geospatial framework to the construction of smart-city spatiotemporal information cloud platforms, we kept exploring the construction contents, construction modes, and service modes of the platforms. This made the framework truly play its role in the standardization of urban spatial data and the integration of departmental information so that it would provide data, infrastructure, platforms, and software services for cities to undergo informatization. Therefore, NASMG entrusts the Chinese Academy of Surveying and Mapping (CASM) to have a thorough survey and consultation to form the Technical Outline of Construction of Smartcity Spatiotemporal Information Cloud Platforms [8], which regulates "Corresponding Author: Prof. Chengming Li, Chinese Academy of Surveying and Mapping, 28 Lianhuachi West Road, Beijing, China; E-mail: 83391860@qq.com

Citation: Li C, Liu x, Yin J (2017) Research on the Evaluate of Chinese Smartcity Spatiotemporal Information Cloud Platforms. Int J Earth Environ Sci 2: 145. doi: https://doi.org/10.15344/2456-351X/2017/145

Copyright: (c) $2017 \mathrm{Li}$ et al. This is an open-access article distributed under the terms of the Creative Commons Attribution License, which permits unrestricted use, distribution, and reproduction in any medium, provided the original author and source are credited. 
Citation: Li C, Liu x, Yin J (2017) Research on the Evaluate of Chinese Smart-city Spatiotemporal Information Cloud Platforms . Int J Earth Environ Sci 2: 145. doi: https://doi.org/10.15344/2456-351X/2017/145

Page 2 of 4

the objectives, plans, requirements, and content of the construction of smart-city spatiotemporal information cloud platforms. This provides a clear direction for selecting the Evaluation-Index Systems suited for smart-city spatiotemporal information cloud platforms.

\section{Establishment requirements}

In the General Framework of Smart-city Evaluation-Index Systems (draft for comment) released by SAC, the general framework of the smart-city Evaluation-Index Systems includes 9 primary indices and 36 secondary indices. After that, SAC conducted expert consultation and public survey on the indicators and revised the indices based on the results of the feedback, and released the National Evaluation Indices of Novel Smart Cities (draft for comment). In this comment, the 9 primary indices do not have a major modification, but the secondary indices are adjusted to finally accommodate 35 secondary indices.

The nine primary indices are information resource security, development mechanism insurance, internet security, innovation capability security, infrastructure intelligence, public service convenience, social management refinement, living environment habitability, and industrial system modernization. In particular, information resource security, development mechanism insurance, internet security, and innovation capability security are four capabilityrelated objective indices reflecting the levels of construction, management, and application. On the other hand, infrastructure intelligence, public service convenience, social management refinement, living environment habitability, and industrial system modernization are five effectiveness-related indices reflecting the main targets and directions of smart-city construction and embodying actual impacts to citizens and governments as well as the subjective feelings of users. Each primary index is comprised of many secondary evaluation elements with each element representing a metric for evaluating the primary indices from a different perspective.

A general framework developed according to the General Framework of Smart-city Evaluation-Index Systems (draft for comment) provides generalized, fundamental, and comprehensive index classification for the evaluation of smart cities. These can guide a city to establish Evaluation-Index Systems for each sub-item from a vertical industrial perspective or a horizontal perspective.

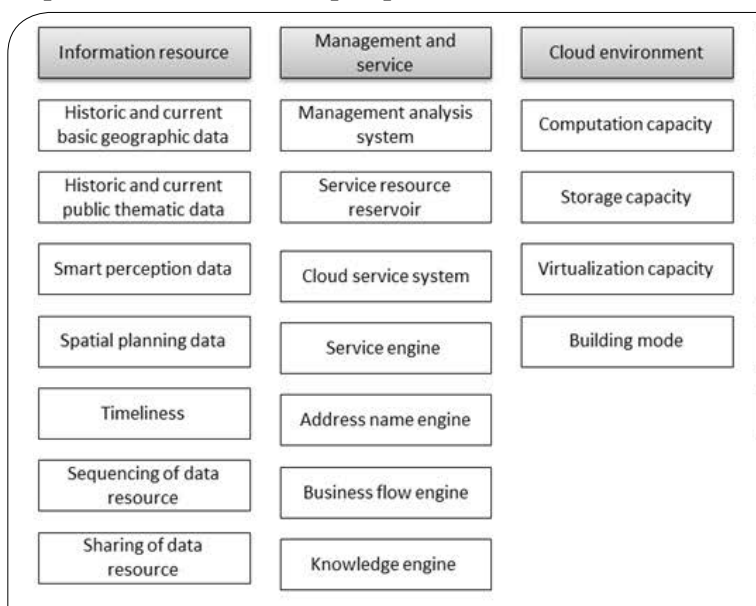

The General Requirement for Establishment of Each Sub-item in Smart-city Evaluation-Index Systems (draft for comment) explicitly gives the requirements for each department to fulfill when establishing an index system. According to the needs from a specific field, it is possible to establish primary and secondary indices for a sub-item by screening some primary indices and referencing evaluation elements of secondary indices of the general framework. The names of primary indices may be properly revised to reflect the features of the sub-fields. The secondary indices, which are qualitative or quantitative indices used in actual implementation for data collection and evaluation, are suggested to include quantitative indices as the major part and qualitative indices as the supplementary part where the number of the indices should not be too high. The secondary indices may be classified as core indices and extended indices. When the core indices are considered as mandatory indices that are to be achieved in a platform construction and the extended indices as other types of indices (such as explorative indices and innovative indices) then they embody construction effectiveness.

\section{Index selection and application}

According to the General Framework of Smart-city EvaluationIndex Systems (draft for comment) and the General Requirement for the Establishment of Each Sub-item in Smart-city Evaluation-Index Systems (draft for comment) in conjunction with the Technical Outline of Construction of Smart-city Spatiotemporal Information Cloud Platforms, we thoroughly considered the features of smartcity spatiotemporal information cloud platforms and determined the Evaluation-Index Systems of smart-city spatiotemporal information cloud platforms to consist of 7 primary indices and 41 secondary indices. Here the primary indices are information resource, management service, cloud environment, application effect, information security, mechanism insurance, and innovative feature. The general framework of an index system is shown in Figure 1.

Smart-city spatiotemporal information cloud platforms are an upgrade from the digital-city geospatial framework in the intelligence era and a four-dimension spatiotemporal criteria for sequencing of large data in smart cities. The platforms are associated with a cloud environment and intelligent thematic application in smart
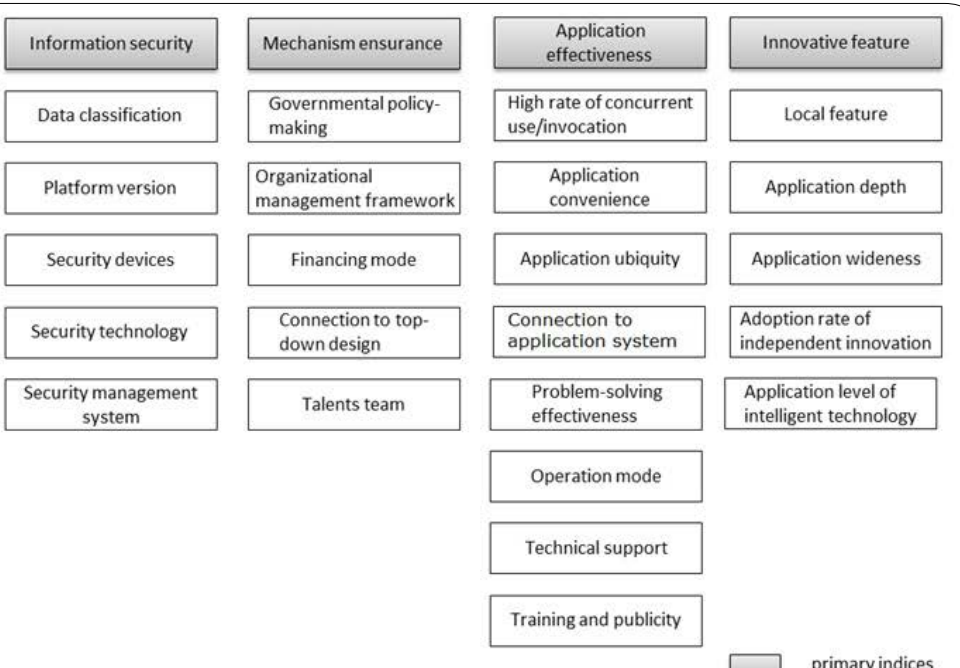

secondary indices

Figure 1: The general framework for the construction evaluation-index systems of smart-city spatiotemporal information cloud platforms 
Citation: Li C, Liu x, Yin J (2017) Research on the Evaluate of Chinese Smart-city Spatiotemporal Information Cloud Platforms. Int J Earth Environ Sci 2: 145. doi: https://doi.org/10.15344/2456-351X/2017/145

Page 3 E of 4

cities which function as a necessary part of smart cities. Therefore, when establishing evaluation indices, we not only need to take into consideration an inheritance from and connection to the general framework of smart-city evaluation index systems, but we must also fully integrate the evaluation index establishment with the state-ofart advancement in the construction of smart-city information cloud platforms.

\begin{tabular}{|c|c|c|c|c|}
\hline primary indices & secondary indices & weight & score & value \\
\hline \multirow{7}{*}{ Information resource } & Historic and current basic geographic data & $5 \%$ & 90 & 4.5 \\
\hline & Historic and current public thematic data & $5 \%$ & 90 & 4.5 \\
\hline & Smart perception data & $4 \%$ & 70 & 2.8 \\
\hline & Spatial planning data & $3 \%$ & 70 & 2.1 \\
\hline & Timeliness & $3 \%$ & 90 & 2.7 \\
\hline & Sequencing of data resource & $2 \%$ & 100 & 2 \\
\hline & Sharing of data resource & $3 \%$ & 100 & 3 \\
\hline \multirow{7}{*}{ Management service } & Management analysis system & $6 \%$ & 90 & 5.4 \\
\hline & Service resource reservoir & $3 \%$ & 85 & 2.55 \\
\hline & Cloud service system & $7 \%$ & 100 & 7 \\
\hline & Service engine & $3 \%$ & 100 & 3 \\
\hline & Address name engine & $2 \%$ & 100 & 2 \\
\hline & Business flow engine & $2 \%$ & 100 & 2 \\
\hline & Knowledge engine & $2 \%$ & 100 & 2 \\
\hline \multirow{4}{*}{ Cloud environment } & Computation capacity & $2 \%$ & 80 & 1.6 \\
\hline & Storage capacity & $2 \%$ & 80 & 1.6 \\
\hline & Virtualization capacity & $2 \%$ & 90 & 1.8 \\
\hline & Building mode & $2 \%$ & 80 & 1.6 \\
\hline \multirow{5}{*}{ Information security } & Data classification & $1.50 \%$ & 100 & 1.5 \\
\hline & Platform version & $1.50 \%$ & 100 & 1.5 \\
\hline & Security devices & $0.50 \%$ & 100 & 0.5 \\
\hline & Security technology & $1.50 \%$ & 100 & 1.5 \\
\hline & Security management system & $1 \%$ & 100 & 1 \\
\hline \multirow{5}{*}{ Mechanism ensurance } & Governmental policy-making & $3 \%$ & 100 & 3 \\
\hline & Organizational management framework & $1 \%$ & 100 & 1 \\
\hline & Financing mode & $2 \%$ & 80 & 1.6 \\
\hline & Connection to top-down design & $1 \%$ & 80 & 0.8 \\
\hline & Talents team & $3 \%$ & 100 & 3 \\
\hline \multirow{8}{*}{ Application effectiveness } & High rate of concurrent use/invocation & $4 \%$ & 80 & 3.2 \\
\hline & Application convenience & $3 \%$ & 80 & 2.4 \\
\hline & Application ubiquity & $3 \%$ & 80 & 2.4 \\
\hline & Connection to application system & $3 \%$ & 90 & 2.7 \\
\hline & Problem-solving effectiveness & $2 \%$ & 90 & 1.8 \\
\hline & Operation mode & $1 \%$ & 90 & 0.9 \\
\hline & Technical support & $2 \%$ & 90 & 1.8 \\
\hline & Training and publicity & $2 \%$ & 100 & 2 \\
\hline \multirow{5}{*}{ Innovative feature } & Local feature & $2 \%$ & 80 & 1.6 \\
\hline & Application depth & $1 \%$ & 80 & 0.8 \\
\hline & Application wideness & $1 \%$ & 80 & 0.8 \\
\hline & Adoption rate of independent innovation & $1 \%$ & 100 & 1 \\
\hline & Application level of intelligent technology & $1 \%$ & 80 & 0.8 \\
\hline $\mathrm{E}$ & \multicolumn{4}{|c|}{89.75} \\
\hline
\end{tabular}


In the general framework for national smart-city evaluation index systems, there are nine primary indices in which public service, social management, ecological habitability, and industrial system are the primary application fields while the cloud platform is playing an indirect role and does not include these indices. In addition to maintain the information resource and mechanism insurance, we adjusted internet security to information security in order to highlight the safety of data. In highlighting this local feature, we adjusted the innovative capability to an innovative feature. In order to promote specificity of index systems, we directly determined the infrastructure to be a cloud environment and the contents of mechanism insurance were directly focused on spatiotemporal information cloud platforms in order to avoid a large similarity with other departmental indices. Given the fundamental features of cloud platform construction, we extended two primary indices; the management service and the application effectiveness of other departments.

In the secondary indices, we specified core indices and extended indices. The core indices emphasize intelligence and independence while the extended indices are fundamental or explorative indices. The secondary indices are a refinement of the primary indices. During the refinement, a priority is given to highlighting those indices such as intelligent perception, automatic interpretation, and an engine that are able to embody intelligent features on the one hand, while the use of independent domestic products is further emphasized for the purpose of security on the other hand.

In practical use, each of the primary and secondary indices is given a weight. The department that is responsible for the construction of smart-city spatiotemporal infrastructure may employ Eqn. 1, based on scoring by experts, to compute an overall score of the construction and application effectiveness.

$$
E=\sum_{i=1}^{41} W i * S i
$$

In Equation 1, $i$ denotes the ordinal number of secondary indices, $W_{i}$ denotes the weight of the $i$-th secondary index, and $S_{i}$ denotes the actual score of the $i$-th secondary index in a hundred-mark system. An $\mathrm{E}$ value in the range of $0-100$ can be used as a reference for the overall evaluation. Here $60 \leq \mathrm{E}<75$ is rated as passing, $75 \leq \mathrm{E}<85$ is good, and $\mathrm{E} \geq 85$ is excellent. Once illegal deployment of confidential data is discerned during a scoring process, the overall evaluation will be rated as failing.

Table 1 is an example of a city in eastern China. Using the evaluationindex systems of smart-city spatiotemporal information cloud platforms and Equation 1, this city get the $\mathrm{E}=89.75$, it means that this city is excellent in the construction of smart-city spatiotemporal information cloud platforms.

\section{Summary}

The purpose of establishing Evaluation-Index Systems of smartcity spatiotemporal information cloud platforms is to clearly evaluate the relevant intelligent capabilities of a city during its cloud-platform construction and evaluate the actual effectiveness brought about by the construction. This then provides support for smart-city construction and guidance as well as promote the city to conduct a purposeful, well-planned, and step-by-step construction. The regional difference in economy, technology, local feature, and management mode among different cities and the requirement that intelligent indices and domestic-technology application indices are given a higher priority.
Conversely, fundamental indices should have lower priorities when selecting indices. A higher the score a city obtains when conducting an evaluation based on the evaluation indices of smart-city spatiotemporal information cloud platforms would suggest a higher level of intelligence and a higher degree of technology domestication. A lower score would not necessarily indicate a worse data foundation, a worse information foundation, or a worse application status in that city, but instead would be attributed to the difference in emphasis.

Recently, the index system in this study has been subjected to evaluation experiments in over 20 pilot cites currently undergoing the construction of smart-city spatiotemporal information cloud platforms. It is now under modification and improvement based on the feedback situations and problems. The system will be ultimately released and proposed for use in the form of a national or industrial criteria. This aims to facilitate the construction of smart-city spatiotemporal information cloud platforms to move forward in a more healthy, ordered, and scientific manner.

\section{Conflict of Intreast}

No authors have a conflict of interest or any financial tie to disclose.

\section{References}

1. Li Chengming, Liu Xiaoli (2013) Investigation and Practice of Digital City to Smart City [J], Bulletin of Surveying and Mapping 1-3.

2. National Administration of Surveying, Mapping and Geoinformation (2016) National Surveying, Mapping and Geoinformation Working Conference Report [EB/OL].

3. A joint document released by eight departments of Ministry of Industry and Information Technology, Ministry of Science and Technology, Ministry of Public Security, Ministry of Finance, Ministry of Land and Resources, Ministry of Housing and Urban-Rural Development and Ministry of Transport. (2014) Instructions About Promoting Healthy Development of Smart Cities (development-reform high-tech [2014] 1770) [Z].

4. Executive Office of the National Development and Reform Commission. (2014) A Notification by Executive Office of the National Development and Reform Commission About Printing and Distributing 'a working system to promote the inter-department coordination and the 2014-2015 working plans'"( development-reform high-tech [2014] 2652) [Z].

5. Standardization Administration of China. (2015) General Framework of Smart-city Evaluation Index System (draft for comments) [Z].

6. Standardization Administration of China. (2015) General Requirement for Establishment of Each Sub-item in Smart-city Evaluation Index System (draft for comments) [Z].

7. Standardization Administration of China. (2016) National Evaluation Indices of Novel Smart Cities (draft for comments) [Z].

8. Standardization Administration of China (2015) Technical Outline of Construction of Smart-city Spatiotemporal Information Cloud Platforms (draft for review) [Z]. 